\title{
Teaching Physics in French Secondary Schools
}

\section{Hulin, Paris}

The Secretary of the French Physical Society (Société Française de Physique) indicates the present status, the obvious shortcomings and the potential improvements in teaching physics in French secondary schools. He hopes that colleagues in other European countries will be encouraged to share their experience which could benefit French physics teaching.

\section{Secondary education in France}

Table 1 is a simplified picture of the French secondary education system as a whole. The following remarks may help:

(i) Attendance at school is compulsory up to 16 years. The 10 million pupils in the education system are accommodated as in
Table 2 and comprise $20 \%$ of the total population:

(ii) Some $7 \%$ of the children are so handicapped that they need special medical care and a further $18 \%$ in section III of the First Cycle are of low level and are oriented to 'professional education'.

(iii) In the Second Cycle, pupils opt for different courses (Table 3 ). The small proportion attracted to science and technology greatly concerns French scientists. However, since the official estimates for the required number of new scientists and engineers is 15000 per year, another serious problem is that only half the scientific pupils can expect to find a posi- tion corresponding to their proper qualifications.

(iv) Two results of the educational system have led to conflicts between political and administrative authorities, parents and teachers: about $10 \%$ of pupils have to repeat from each form, and only two-thirds of candidates obtain their 'baccalauréat'.

(v) There have also been internal conflicts within the teaching profession arising from the privileged salaries and workloads of 'professeurs agrégés' and the extensive use of underqualified auxiliaries. For physical sciences, about 190 'professeurs agrégés' and about 50 'professeurs certi-

Table 1 French secondary education system

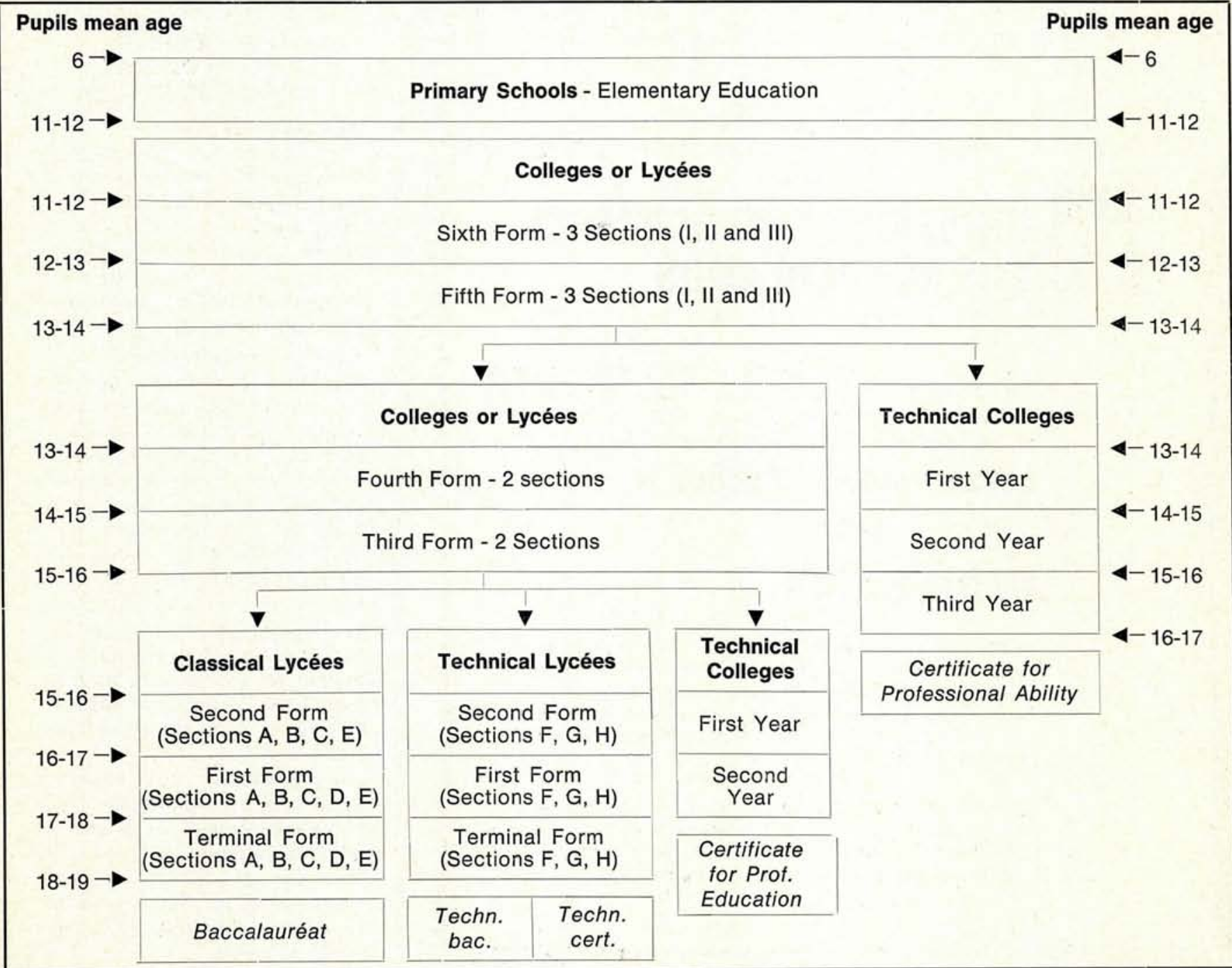


fiés' are selected annually by competition. Because of the urgent need for teachers of 'new maths', the underqualified auxiliaries include some who have just taken a 'baccalauréat' in ... literature!

\section{Psycho-sociological background}

The parents of most secondary school pupils have had no direct contact with secondary teaching, since they themselves left school at 13 or 14. They find it difficult to appreciate the demands of secondary education for homework, reading,... sleep, however fascinating the television programmes may be ! Other rapid social changes (urbanization, erosion of family life, growing influence of mass media) have increased the gap between the educational system and the public.

The compulsion to attend school until 16 is not well understood and is rejected by a significant proportion of the population. The consequence of the decline in relative value of the 'baccalauréat' is also not appreciated, since many parents expect their offspring to become doctors, civil servants, teachers, etc., after obtaining it.

Problems also arise from the demands by universities for better-prepared students and the inability of low-level teachers to raise the standard of unmotivated pupils. Finally, the ideological acceptance of secondary education is now in doubt, in contrast with the attitude to universal elementary education in the 1880 s.

This psycho-sociological background restricts the potential to modify even very technical components in the teaching of physical sciences, though it may not seem to be directly relevant.

\section{Teaching physical sciences}

There are two points to stress:

Firstly, physics and chemistry are taught by the same teacher as 'Physical Sciences', with the disadvantages of neglecting some chemistry with biological emphasis and a tendency to reduce chemistry problems to physics.

Secondly, physical sciences are not introduced suficiently early or emphatically in the First Cycle to enable pupils to sensibly choose this option for their Second Cycle studies. And even when they appear in the Second Cycle, physical sciences are still second rank in comparison with mathematics.

Table 2

Elementary schools

Secondary schools

First Cycle : sections I and II .

section III (lower level) . .
Short Second Cycle (technical college).

$5,000,000$

$2,200,000$

400,000

600,000

Long Second Cycle (classical and technical lycées) . . . . 800,000

Universities and similar establishments

800,000

Table 3

(A) literature and philosophy

(B) socio-economic sciences

(C) mathematics and physics

(D) biological sciences

(E) mathematics and technology

$(\mathrm{F}, \mathrm{G}, \mathrm{H})$ technical sections.

Number

88000

15000

32000

55000

9000

60000
Percentage

34

5.5

13

21

3.5

23
This situation probably originates in the literary background of the most influential personalities in France: essentially, they themselves failed to understand any mathematics which they consider a major personal problem and, as for physics, 'beyond' mathematics, that could simply be ignored! They are preoccupied with organization, administration or finance, and leave the technical aspects of physical sciences to low-class helots. Finally, there remains the feeling of 'cartesianism' (deriving little from Descartes), that a methodical intellect can solve all problems and unveil all the mysterious laws of nature. Experiments are simply not understood: just sit down with paper and pencil, and think! Clearly, physical sciences do not have a fertile soil from which to grow and prosper.

Physics and chemistry have been reluctant to up-date terminology, concepts and theories: only 20 years ago, courses still presented the atomic hypothesis. The courses appear as fossilized layers, almost as abruptly disconnected as geological strata. There is little attempt to relate physics and chemistry to the technological developments in daily life. There has been no effective presentation of the unity of physics, nor stress of its essential characteristic as an experimental science based on a permanent dialectic between theory and experimentation. 'Laws' are emphasized to the neglect of general principles and methods. Consequently, physics appears as a catalogue of disconnected recipes.

Another distortion arises from the excessive emphasis on examinations. Because examiners find it difficult to prepare a 'true' physics problem without danger of contestation, ques- tions are reduced to low-level mathematics adorned with elementary numerical applications. Some dubious theories, such as the rediscovery dogma, now underly the whole system. The promoters do not realize the difficulties of 'rediscovering' in a few weeks the final solution of a major riddle in the history of physics.

It must be said, however, that in the past 20 years the teaching of physics and chemistry has evolved somewhat; for example, pupils may themselves carry out manipulations more frequently.

The 'new mathematics' tsunami which reached France about 12 years ago has considerably influenced the teaching of physics here. Two major criticisms are: first, the logical progression in teaching of the new mathematics does not equip the pupils for physics; and, second, that the benefits of increased proficiency claimed for the new mathematics have not been achieved. In most cases, the practical application of the new mathematics is almost catastrophic. Moreover, whilst the new mathematics does provide some powerful tools (for example, in linear algebra), the physics teachers have not been trained to use them.

\section{Present initiatives}

After this rather critical and pessimistic picture, it would be gratifying to present spectacular countermeasures and to describe their first results. Unfortunately, we are still far from being able to present even a first balance.

In May 1969, the French Physical Society organized meetings with members of the 'Union des Physiciens' 
(Physics Teachers' Association) and of the French Chemical Society to examine the main problems. From this initiative, a Ministerial Commission for the Renewal of Education in Physics, Chemistry and Technology was created in May 1971. The President of the Commission, A. Lagarrigue, also Head of Orsay Linear Accelerator Laboratory, persuaded renowned scientists to approve a statement that 'experimental sciences, including physics, chemistry, biology and technology, should appear as a fundamental discipline, with a sufficient timetable, at all teaching levels', and that 'this teaching should properly complement mathematics education in order to show clearly the connections between the theoretical and experimental approaches.'

Our main concern was to promote the introduction of physical sciences in the First Cycle. Because of the lack of tradition and of the need to consider 'technology' courses, pedagogical research of a fundamental character was needed.

Unfortunately, later in 1971, the Ministry decided to reform the Second Cycle within two or three years, and urged the Commission to give priority to the corresponding teaching of physical sciences. Several sub-commissions prepared new programmes for the Second Cycle, whilst a working group was charged with fundamental research into teaching of beginners:

(i) The new programmes for the Second Cycle were rapidly proposed on the basis of work carried out previously by members of the 'Union des Physiciens'. For the Second Form, about one-third chemistry, one-third d.c. current phenomena and electronics initiation, and one-third kinematics and dynamics; for the First Form, the physics was about one-half on vibrations and waves phenomena and one-half on the notion of energy, the concept of field and d.c. current with more mathematics; for the Terminal Form, vibrations and waves involved trigonometric functions, mechanics extended to rotation and angular momentum, atomic physics...

We deeply feel that we lacked preliminary studies for this project, although we hope to have minimized the risks by voluntarily restricting our ambitions. The only 'general' principle is invariance which introduces a limited number of concepts. These programmes are now being tested in about 30 classes. Certainly, we shall not be revolutionary. We shall not even make up for lost time. We hope that we have not started a catastrophe, but have induced progress in the right direction.

(ii) The 'working group' is headed by G. Delacote, a member of the IUPAP Commission on Physics Education. Its task is the building up of the elements of initiatory teaching of the First Cycle. Several 'units' have been prepared to correspond to three months' teaching in a 'real' class.

Obviously, these first efforts are limited compared with the problems, and they are on a completely different scale from the PSSC or the Nuffield Foundation Project. Moreover, we are disquieted by several serious obstacles. First, the administrative authorities are extremely reluctant to admit the very principle of the introduction of physical sciences into the Sixth and Fifth Forms. Yet, we believe that would be absolutely essential to begin to put France on an equal footing with other European countries.

Second, one of the main ideas of our Commission is that teachers must have free time to simply talk with pupils, to answer their questions about, for example, the last Apollo flight, and to introduce some history, etc. This is completely against French tradition in schools: many colleagues seem to fear that less formalized teaching could not be 'serious'.

Third, traditionally, teachers have been accustomed to 'not being able to complete the programme'; they are initially hostile to concentration on a few principles and concepts, and consider this will automatically result in a low-level education.

Finally, there remains an enormous financial problem: increasing the part of experimental teaching and manipulations in comparison with conventional courses means that the laboratory equipments of the lycées must be considerably enlarged; in addition, it is necessary to 'teach the teachers', and this also implies a considerable effort. A provisional budget has just been established: it amounts to some FF $400,000,000$ for the whole operation, extending over 10 years. It is not yet known what answer will be given.

It will probably appear to the reader that our problems are often more original than the solutions we present. May we end this short account with an anecdote which perhaps will convince him that the task we are faced with is formidable enough to excuse the shyness of our first reactions? At the beginning of this year, one colleague, teaching in the Second Form of a Paris lycée, held a brief inquiry on the initial ideas his pupils had about physics; to the question 'What do you think that an atom is?', he got the answer: "I think it is a very nasty liquid'. To the question 'How does one know that the earth is revolving around the sun, and not the contrary?', he received this peremptory reply: 'It is just a theory of scientists but nobody can prove anything about it'; (in both cases, the pupils belonged to wellestablished families). Should we consider it characteristic of French society that it is both preatomistic and precopernician?

\section{Society News}

\section{Member Societies}

\section{Danish Physical Society}

The new Secretary is P. Lawaetz, Physics Laboratory III, Building 309-C, Technical University of Denmark,

Lundtofte, DK-2800 Lynby.

\section{French Physical Society}

The new President is R. Castaing (Orsay).

\section{Institute " Ruder Boskovic "}

The new Secretary is I. Slaus, Institute "Ruder Boskovic", Bijenicka 54, P.O. Box 1016, YU-41001 Zagreb.

\section{The Israel Physical Society}

The new President is Y. Eisenberg

(Rehovot) and the new Secretary is A. Shapira,

Department of Physics, Weizmann Institute of Sciences, Rehovot.

\section{Romanian National Committee for Physics}

The new President is $\mathbf{S}$. Titeica

(Bucharest).

\section{Swedish Physical Society}

The new President is L. Minnhagen (Lund) and the new Secretary is

I. Otterlund,

Department of Physics, University of Lund, Sölvegatan 14, S-223 62 Lund.

\section{Swiss Physical Society}

The new President is J.L. Olsen (Zurich).

\section{Turkish Physical Society}

The new Secretary is F. Kortel, Faculty of Science, Istanbul.

\section{Associate Members}

The following organizations have decided to join EPS as Associate Members:

Comitato Nazionale per l'Energia

Nucleare (CNEN), Rome, Italy;

Kodak-Pathe, Vincennes, France. 